7. Reprod. Fert. (1969) 19, 491-502

\title{
AN EXPERIMENT WITH HETEROSPERMIC INSEMINATION IN CATTLE
}

\author{
R. A. BEATTY ${ }^{1}$, G. H. BENNETT ${ }^{2}$, J. G. HALL ${ }^{3}$, J. L. HANCOCK ${ }^{3}$ * \\ AND D. L. STEWART ${ }^{2}$ \\ ${ }^{1}$ Institute of Animal Genetics, Edinburgh, ${ }^{2}$ Ministry of Agriculture, Fisheries and Food, \\ Cattle Breeding Centre, Shinfield, Reading, and ${ }^{3}$ Animal Breeding Research Organisation, \\ Edinburgh
}

(Received 24th October 1968)

\begin{abstract}
Summary. Friesian cows were inseminated with semen mixtures containing equal numbers of spermatozoa from a Friesian and a Hereford bull. The five bulls of each breed gave twenty-five possible combinations. The paternity of calves was established by inspection of colour and conformation. Heterospermic indices were calculated to express the relative ability of sires to father offspring after mixed insemination. There were significant differences between the heterospermic indices of bulls, the maximum observed difference being twenty-one-fold. The indices were consistent over two series. The homospermic index was defined as the 16-week non-return rate after normal single first inseminations. The heterospermic index established differences between bulls more efficiently than the homospermic index; one estimate showed that the heterospermic method needed less than $1 / 170$ th the number of inseminations required by the homospermic method. The homospermic index was predictable from the heterospermic index, the regression coefficient having a significance level of $0.05>P>0.025$. The initial spermatozoan concentration of a bull's semen (before dilution) was highly correlated with the heterospermic index. Measures of semen quality based on the morphology and staining affinity of spermatozoa predicted heterospermic and homospermic indices non-significantly but in the right direction.
\end{abstract}

\section{INTRODUCTION}

Heterospermic insemination with mixed semen from two or more sires is to be contrasted with homospermic ('normal') insemination from the semen of only one sire. There is a considerable early literature (see Kushner, 1954). In experiments with the mouse (Edwards, 1955) and the rabbit (Beatty, 1957, 1960; Napier, 1961) it has been found that the numbers of offspring produced by two sires after heterospermic insemination with equal numbers of spermatozoa are commonly very unlike, some sires being termed 'heterospermically superior'

* Present address: Royal Veterinary College, London. 
to others. In the rabbit, heterospermic superiority and superiority in homospermic conception rate were in the same direction and also in the same direction as superiority indicated by in vitro tests of semen quality. Further, the relative heterospermic superiority of rabbit sires remained virtually constant over periods of time. Heterospermic superiority could be assessed with considerable precision. Thus, heterospermic insemination appeared to afford a peculiarly efficient means of predicting 'normal' sire fertility. The present work extends the enquiry to cattle, with the following questions in mind. Do bulls differ in their heterospermic performance? Are the heterospermic differences constant over a period of time? To what extent is the heterospermic performance of a bull a predictor of his homospermic performance? What is the relative efficiency of heterospermic and homospermic evaluation of bull fertility?

\section{MATERIALS AND METHODS}

General plan of experiment

Five Friesian (F) and five Hereford $(\mathrm{H})$ bulls were to be used, with Friesian cows as dams. Each insemination was to be with mixed semen containing 10 million spermatozoa from one $\mathrm{F}$ bull and 10 million from one $\mathrm{H}$ bull, twentyfive combinations being possible. Each combination was to be used for the insemination of at least fifteen cows in a Series 1 and at least another fifteen in an immediately subsequent Series 2, giving a planned total of at least 750 inseminations, though this would depend on the scale of cooperation received from farmers. Each offspring was to be traced to its sire by colour, the FriesianHereford crosses being marked by the dominant Hereford-type white face. The beef-type conformation of crosses gave additional though less reliable evidence. Spermatozoa were classified according to their staining affinity and according to the morphological features of the acrosome. Because 'dead' spermatozoa are characteristically altered in these respects, it was the intention to use the two criteria to make independent estimates of the 'dead' spermatozoan content of the samples used. The various correlations with initial spermatozoan concentration would also be studied. There would be no formal control inseminations, but the 16-week non-return rate available from the Centre's records would be used as a measure of the 'normal' fertility of each bull. Each cow would be used only once in the experiment.

\section{Detailed procedure}

The pooled ejaculates collected from one bull during 1 day were termed a 'semen collection'. Duplicate nigrosin-eosin-stained smears were made from each collection by the method of Hancock (1957). The slides of the whole experiment were coded, and scanned in a randomized order by one observer, I. McLachlan, 100 spermatozoa per slide being classified into 'uniformly stained' (whole head stained), 'part stained' (head part stained) or 'unstained' (head not stained). With the slides again coded and in a randomized order, the percentage of 'capless spermatozoa' (acrosome cap structurally altered or missing) was determined among 100 spermatozoa per slide by another observer, M. Rennie. Initial spermatozoan concentration in units of $10^{8} / \mathrm{ml}$ 
was determined photometrically to about $1 \%$ accuracy by the method of Cox \& Melrose (1953).

Each semen collection was diluted with standard diluent to a final concentration of 20 million spermatozoa/ml. The diluent was: solution of skim milk powder $9.0 \% \mathrm{wt} / \mathrm{vol}$ in distilled water heated to $92^{\circ} \mathrm{C}$ for $10 \mathrm{~min}, 92.5 \%$; yolk of egg, $6.0 \%$; glycerol, $1.5 \%$; streptomycin calcium chloride $500 \mu \mathrm{g} / \mathrm{ml}$. Each insemination mixture comprised $0.5 \mathrm{ml}$ diluted semen from each of the two bulls concerned. All inseminations were with ' 1 day' semen on 'first service' Friesian cows. The insemination mixtures were made in a pre-arranged randomized order within each series. Each semen collection contributed to one and only one insemination mixture. Series 1 inseminations were carried out from 13th May to 13th June 1964 and Series 2 from 14th June to 16th July 1964. Within 7 days of birth, but occasionally up to 3 weeks, the paternity of each calf was established by recognizing the Hereford characteristics in the Hereford-Friesian crosses. The sex of calves was noted.

\section{RESULTS}

In Series 1, 322 heterospermic inseminations were carried out, 178 cows calved, and there were 185 offspring, including seven pairs of twins. In Series 2, there were 186 inseminations, giving 95 calvings and 97 offspring, including two pairs of twins. Three pairs of twins were all sired by Herefords, four pairs by

TABLE 1

RESULTS OF HETEROSPERMIC INSEMINATION

\begin{tabular}{|c|c|c|c|c|c|c|c|c|c|c|}
\hline \multirow{3}{*}{$\begin{array}{c}\text { Hereford } \\
\text { sires }\end{array}$} & \multicolumn{5}{|c|}{ Series $1: \mathcal{N}=185$} & \multicolumn{5}{|c|}{ Series $2: \mathcal{N}=97$} \\
\hline & \multicolumn{5}{|c|}{ Friesian sires } & \multicolumn{5}{|c|}{ Friesian sires } \\
\hline & $F 19$ & $F 24$ & $F 30$ & $F 31$ & F32 & $F 19$ & $F 24$ & F30 & F31 & $F 32$ \\
\hline H11 & $\begin{array}{ll}1 & 5\end{array}$ & 0 & $\begin{array}{ll}7 & \\
& 1\end{array}$ & 5 & 4 & - & 3 & 1 & 1 & 6 \\
\hline H12 & $\begin{array}{ll}3 & \\
& 2\end{array}$ & 6 & $\begin{array}{ll}12 & \\
& 0\end{array}$ & 8 & 5 & 0 & 3 & 2 & - & 1 \\
\hline H14 & $\begin{array}{ll}9 & \\
& 3\end{array}$ & - & 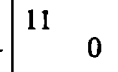 & 6 & - & 0 & 8 & 2 & 5 & 2 \\
\hline H15 & 3 & 5 & 1 & 3 & 6 & 3 & 2 & 3 & 4 & 0 \\
\hline $\mathrm{H} 16$ & 0 & 0 & $\begin{array}{ll}3 & 6\end{array}$ & 5 & 3 & 8 & 1 & $\begin{array}{ll}0 & \\
& 3\end{array}$ & 0 & 2 \\
\hline
\end{tabular}

Example: in top left cell, a mixed inseminate gave one offspring from bull F19 and five from H1l

Friesians, while two pairs were bipaternal. Of the planned twenty-five combinations per series, two were lacking in Series 1 (no semen collections), while in Series 2 there was no semen for one combination and in another combination semen was available but yielded no heterospermic progeny. The heterospermic data are summarized in Table 1. The counts from eight slides accidentally 
stained with nigrosin instead of nigrosin-eosin were adjusted by applying small corrections derived from additional observations in which ejaculates from three of the bulls were split between the correct and incorrect types of stain. The visual assignments to breed were all correct in eighteen calves submitted to a blood-typing check. Nevertheless, one of the eighteen calves could not have been sired by either of the sires contributing to the mixed semen, or else the wrong dam was offered for blood-typing; another of the eighteen calves could not have been born from its putative dam. The overall percentage of male progeny in the heterospermic experiment was $47 \cdot 16 \pm 2 \cdot 97$. A detailed $\chi^{2}$ analysis showed that heterogeneity in sex ratio did not approach significance at any level tested.

Indices of fertility and semen quality in the ten bulls

The object in this section is to set out (in Table 2) comparative figures or 'indices' for the homospermic and heterospermic fertility and for the in vitro semen qualities of each bull, averaged over the two series.

TABLE 2

FERTILITY AND SEMEN QUALITY

\begin{tabular}{|c|c|c|c|c|c|c|c|c|c|c|}
\hline \multirow{3}{*}{ Bull } & \multicolumn{2}{|c|}{ Homospermic data } & \multicolumn{8}{|c|}{ Heterospermic data } \\
\hline & \multirow[b]{2}{*}{$\begin{array}{c}\text { No. } \\
\text { cows } \\
\text { insem- } \\
\text { inated }\end{array}$} & \multirow{2}{*}{$\begin{array}{c}16-\text { week } \\
\text { non return } \\
\text { rate } \\
\text { Feb.-Oct. }\end{array}$} & \multicolumn{2}{|c|}{ Heterospermic fertility } & \multicolumn{6}{|c|}{ In vitro qualities of semen collections } \\
\hline & & & $\begin{array}{c}\text { No. } \\
\text { calves } \\
\text { sired }\end{array}$ & $\begin{array}{c}\text { Heterospermic } \\
\text { index } \\
\pm \\
\text { S.E. }\end{array}$ & $\begin{array}{c}\text { Collec- } \\
\text { tions } \\
\text { per } \\
\text { bull }\end{array}$ & $\begin{array}{c}\text { Initial } \\
\text { spermatozoan } \\
\text { concentration } \\
\left(10^{8} / \mathrm{ml}\right)\end{array}$ & $\begin{array}{c}\% \\
\text { uniformly } \\
\text { stained }\end{array}$ & $\begin{array}{c}\% \\
\text { part } \\
\text { stained }\end{array}$ & $\begin{array}{c}\text { Total } \\
\% \\
\text { stained }\end{array}$ & capless \\
\hline $\begin{array}{l}\text { F19 } \\
\text { F24 } \\
\text { F30 } \\
\text { F31 } \\
\text { F32 } \\
\text { H11 } \\
\text { H12 } \\
\text { H14 } \\
\text { H15 } \\
\text { H16 }\end{array}$ & $\begin{array}{r}655 \\
1113 \\
1007 \\
1116 \\
1019 \\
739 \\
762 \\
178 \\
683 \\
1056\end{array}$ & $\begin{array}{l}64 \cdot 58 \\
65 \cdot 50 \\
64 \cdot 75 \\
69 \cdot 35 \\
67 \cdot 12 \\
63 \cdot 46 \\
65 \cdot 62 \\
60 \cdot 11 \\
66 \cdot 47 \\
68 \cdot 37\end{array}$ & $\begin{array}{r}20 \\
28 \\
49 \\
37 \\
29 \\
31 \\
10 \\
8 \\
25 \\
45\end{array}$ & $\begin{array}{r}2.76 \pm 0.46 \\
7.31 \pm 1.08 \\
15.68 \pm 1.79 \\
14.96 \pm 1.96 \\
11.39 \pm 1.61 \\
11.38 \pm 1.35 \\
2.24 \pm 0.40 \\
1.25 \pm 0.28 \\
6.31 \pm 0.78 \\
26.72 \pm 2.65\end{array}$ & $\begin{array}{r}9 \\
9 \\
10 \\
10 \\
9 \\
9 \\
10 \\
8 \\
10 \\
10\end{array}$ & $\begin{array}{r}8.4 \\
8.7 \\
13.0 \\
11.5 \\
9.0 \\
12.5 \\
8.6 \\
5 \cdot 6 \\
9.7 \\
11 \cdot 3\end{array}$ & $\begin{array}{l}5 \cdot 7 \\
7 \cdot 4 \\
5 \cdot 6 \\
4 \cdot 0 \\
2 \cdot 2 \\
4 \cdot 0 \\
5 \cdot 5 \\
9 \cdot 4 \\
8 \cdot 1 \\
8 \cdot 2\end{array}$ & $\begin{array}{l}19 \cdot 8 \\
15 \cdot 6 \\
13 \cdot 6 \\
14 \cdot 1 \\
11 \cdot 2 \\
13 \cdot 7 \\
16 \cdot 8 \\
26 \cdot 9 \\
21 \cdot 6 \\
25 \cdot 4\end{array}$ & $\begin{array}{l}25 \cdot 6 \\
23 \cdot 0 \\
19 \cdot 2 \\
18 \cdot 1 \\
13 \cdot 4 \\
17 \cdot 7 \\
22 \cdot 2 \\
36 \cdot 3 \\
29 \cdot 8 \\
30 \cdot 7\end{array}$ & $\begin{array}{r}12 \cdot 4 \\
12 \cdot 7 \\
10 \cdot 6 \\
11 \cdot 6 \\
8 \cdot 7 \\
10 \cdot 6 \\
14 \cdot 7 \\
22 \cdot 9 \\
18 \cdot 2 \\
17 \cdot 0\end{array}$ \\
\hline $\begin{array}{l}\mathrm{F} \text { mean } \\
\mathrm{H} \text { mean }\end{array}$ & & $\begin{array}{l}66 \cdot 26 \\
64 \cdot 81\end{array}$ & & $\begin{array}{r}10 \cdot 42 \\
9 \cdot 58\end{array}$ & & $\begin{array}{r}10 \cdot 1 \\
9.5\end{array}$ & $\begin{array}{l}5 \cdot 0 \\
6 \cdot 5\end{array}$ & $\begin{array}{l}14.9 \\
20.8\end{array}$ & $\begin{array}{l}19 \cdot 9 \\
27 \cdot 3\end{array}$ & $\begin{array}{l}11 \cdot 2 \\
16.7\end{array}$ \\
\hline $\begin{array}{l}\text { Grand } \\
\text { mean }\end{array}$ & & $65 \cdot 53$ & & $10 \cdot 00$ & & $9 \cdot 8$ & $5 \cdot 7$ & $17 \cdot 9$ & $23 \cdot 6$ & 13.9 \\
\hline
\end{tabular}

The 'homospermic index' was chosen in advance as the 16-week non-return rate for the ten bulls between February and October 1964, from the Centre's records. The data were too scanty to justify the setting up of indices for the separate periods of the two series, or even for the whole period of the heterospermic experiment. The overall index was $65.53 \%$.

The 'heterospermic index' expressing the relative power of each bull to sire offspring after heterospermic insemination, was estimated from the data of Table 1 by computing ten maximum likelihood constants arranged arbitrarily 
to total 100 (see Appendix). Significant differences existed between the indices, and their small standard errors show that they are determined with some precision. The indices were consistent between the two Series. The '16-week heterospermic non-return rate' was $68.63 \%$ in Series $1,67.20 \%$ in Series 2, and the 'heterospermic calving rate' was $55.3 \%$ in Series $1,51.1 \%$ in Series 2 . The heterospermic non-return rate and calving rate do not appear in Table 2 because they were of limited utility for various reasons; in particular, the effective sire could not be identified when a cow returned to service or failed to calve.

The 'initial spermatozoan concentration' index was obtained by averaging semen collections per bull within series, and then averaging each bull over the two series.

The indices for staining affinity and the percentage capless were obtained by successive averaging of the two slides per semen collection, the semen collections per bull within series, and the bull averages over the two series. The variates in Table 2 are the percentages uniformly stained, the percentage part stained and the total percentage stained (the latter being also 100 minus the percentage unstained); and the percentage capless. Angular transformation of percentages was considered unnecessary.

\section{Relationships between bull indices}

The object in this section is to examine relationships between the columns of Table 2, chiefly by means of the unweighted correlations listed in Table 3.

TABLE 3

CORRELATIONS BETWEEN BULL INDICES OF TABLE 2 AFTER LOG TRANSFORMATION OF HETEROSPERMIC INDEX

\begin{tabular}{|c|c|c|c|c|c|c|}
\hline & $\begin{array}{l}\log \text { Hetero- } \\
\text { spermic } \\
\text { index }\end{array}$ & $\begin{array}{c}\text { Initial } \\
\text { spermatozoan } \\
\text { concentration }\end{array}$ & $\begin{array}{c}\% \\
\text { uniformly } \\
\text { stained }\end{array}$ & $\begin{array}{c}\% \\
\text { part } \\
\text { stained }\end{array}$ & $\begin{array}{c}\text { Total } \\
\text { percentage } \\
\text { stained }\end{array}$ & $\begin{array}{l}\% \\
\text { capless }\end{array}$ \\
\hline $\begin{array}{l}\text { 16-week homospermic } \\
\text { non-return rate }\end{array}$ & $+0 \cdot 690^{*}$ & +0.476 & -0.554 & -0.309 & -0.402 & -0.414 \\
\hline $\begin{array}{l}\log \text { Heterospermic } \\
\text { index }\end{array}$ & & $+0.839 * * *$ & -0.583 & $-0 \cdot 380$ & -0.466 & -0.523 \\
\hline $\begin{array}{l}\text { Initial spermatozoan } \\
\text { concentration }\end{array}$ & & & -0.543 & -0.473 & -0.524 & -0.576 \\
\hline $\begin{array}{l}\text { Percentage uniformly } \\
\text { stained }\end{array}$ & & & & $+0.716^{* *}$ & $+0.847 * * *$ & $+0.829 * * *$ \\
\hline $\begin{array}{l}\text { Percentage part } \\
\text { stained }\end{array}$ & & & & & $+0.978 * * * *$ & $+0.920^{* * * *}$ \\
\hline $\begin{array}{l}\text { Total percentage } \\
\text { stained }\end{array}$ & & & & & & $+0.950 * * * *$ \\
\hline
\end{tabular}

The heterospermic indices were first transformed into logarithms (see Appendix).

There is, first, a certain harmony in the results relative to male fertility. 
If we allot signs to the variates on a priori grounds, i.e. a positive sign to factors in which an increase is in the direction of increased male fertility (homospermic and heterospermic indices, and presumably also the initial spermatozoan concentration), and a negative sign to factors in which an increase is in the direction of decreased male fertility (staining and capless indices), then the sign of the correlation obtained from the data is always the same as the product of the signs allotted a priori to the two variables being correlated.

The relationship of prime interest is that the homospermic index is correlated positively and significantly with, and only with, the log heterospermic index $(\mathrm{r}=$ $+0.690 ; 0.05>P>0.025$ ). The relationship can be presented more usefully as a predictive equation: $\mathrm{Y}=61.95+4.23 \log \mathrm{X}$, where $\mathrm{Y}$ is the homospermic index and $\mathrm{X}$ is the heterospermic index (see Text-fig. 1) This means that a rise

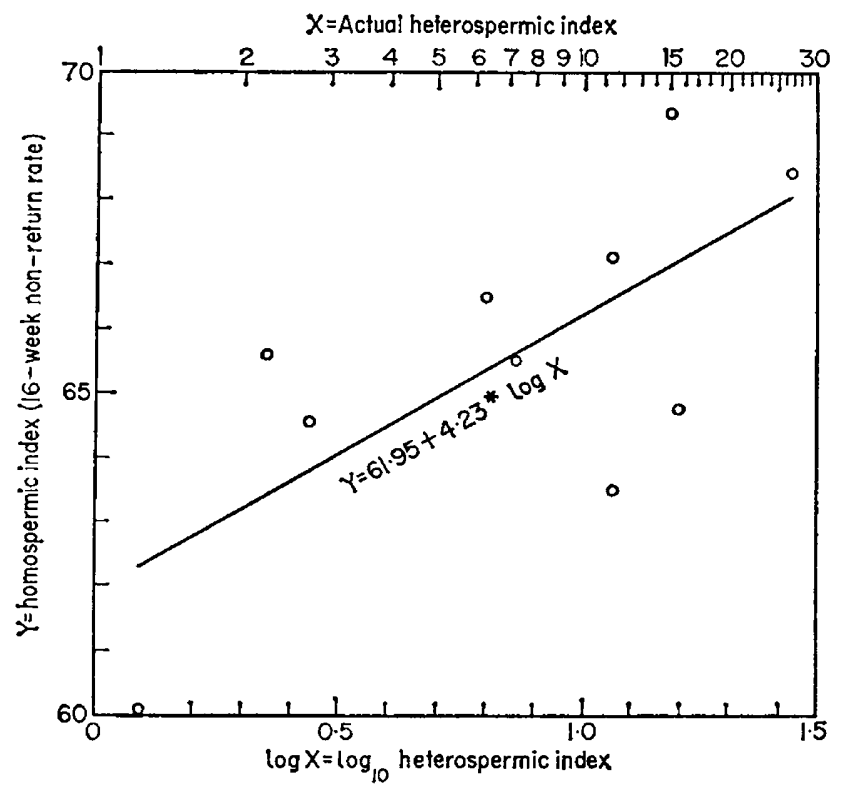

TEXT-FIG. 1. Relation between heterospermic and homospermic indices.

of 1.0 in the $\log$ heterospermic index (i.e. a ten-fold increase in the actual heterospermic index) predicts a rise of 4.23 in the homospermic index. The correlation and the regression coefficient necessarily have an identical significance level. The homospermic index is correlated non-significantly but in the right direction relative to male fertility with the following, in decreasing order of absolute value of correlation: percentage uniformly stained, initial spermatozoan concentration, percentage capless, total percentage stained and percentage part stained. Bull $\mathrm{H} 14$ is picked out as the 'worst' bull by every index in Table 2.

The log heterospermic index is correlated positively, highly and significantly with the initial spermatozoan concentration. There are very high and significant correlations between the percentage capless on the one hand and each of the three measures of staining affinity; the measures of staining affinity are them- 
selves highly correlated with one another. All remaining correlations are nonsignificant.

\section{The relative efficiency of heterospermic and homospermic insemination in differentiating between bulls}

The labour of measuring bull fertility may be taken as proportional to the number of inseminations required. To obtain equal precision in the homospermic and heterospermic methods of assessing bull fertility, i.e. to obtain the same significance level in both methods, what is the relative amount of labour involved? An example will, perhaps, suffice, based on an arbitrary though representative set of conditions. Imagine a homospermic experiment in which each of two bulls A and B is used to inseminate 80,122 cows (total, 160,244 cows), and let the non-return rate be $65.829 \%$ from A and $65.237 \%$ from $\mathrm{B}$. The homospermic fertility difference between bulls is the difference between the two percentages, with a significance level of $P=0.0126$. Now imagine a heterospermic experiment with 476 inseminates of a mixture of equal numbers of spermatozoa from A and B. Assuming a nominal calving rate of $50 \%$, there would be 238 offspring; let $57.98 \%$ of these be sired by A and $42.02 \%$ by $B$. The difference in heterospermic fertility between bulls is tested by the significance of the deviation of the two percentages from a 50:50 expectation, $P$ again being 0.0126 . The figures have been set up to reflect the finding described above, that a 4.232 rise in homospermic index is associated with a tenfold increase in heterospermic index. It will be seen that, to differentiate between two bulls with equal significance, the 476 heterospermic inseminations were matched by no less than 160,244 homospermic inseminations. The heterospermic method is therefore estimated to be more efficient than the homospermic by a factor of 340 , the rounded-off ratio of the two preceding figures. This applies to ideal results in which all tangible variation can be ascribed to bull differences. In the present experiment, the residual error in the heterospermic results was double its expected value, and the factor of 340 should therefore be halved. On the other hand, there would undoubtedly be some intangible error in the homospermic results, though no estimate of it is available, and the factor of 340 should be increased by an unknown amount. Thus the final estimate in this experiment is that the heterospermic test is $170+$ times as efficient as the homospermic.

\section{DISCUSSION}

Bulls differ significantly in their heterospermic performance, the maximum observed difference being the 21-fold one between bulls H14 and H16. There was no significant series/bull interaction, meaning that the heterospermic indices of the bulls could be considered consistent over the two series. This constancy over a period of time is becoming a feature of studies in heterospermic insemination, since it applied also to rabbits over a period of 10 months (Beatty, 1960) and seems also to be apparent in mouse data (Edwards, 1955). However, the heterospermic indices in the present work do not quite explain all the variation, the 'pooled remainder' described in the Appendix being significant, and 
there is room for the operation of such factors as interactions peculiar to certain combinations of bulls, or ejaculate variation within bulls, or the errors in recording and manipulation that must inevitably occur in a cooperative enterprise involving many scientists, inseminators and farmers. Indeed, a bloodtyping check showed error in the recorded parentage of two calves. Error of this nature is presumably random and should not bias the heterospermic indices, though it decreases the precision with which they are determined. In the rabbit it is much easier to maintain exact experimental conditions, and the 'remainder' variation was non-significant.

How well does the heterospermic index of a bull predict his homospermic index? Essentially, the heterospermic index expresses a relative number of calves, and it would be logical to correlate it with the homospermic calving rate. The latter was not available and the best estimate of 'normal' bull fertility was the homospermic 16-week non-return rate for each bull available from the Centre's records. The usefulness of the heterospermic index may be judged from the finding that it was the only significant predictor of homospermic non-return rate. A ten-fold increase in heterospermic index predicts a rise of 4.23 in the 16-week, homospermic non-return rate. Homospermic differences between bulls are, as it were, exaggerated and more easily detectable in the heterospermic test, as also in the rabbit experiments (Beatty, 1960). The scale of the prediction may be visualized from an example calculable from Table 2. If homospermic inseminations had been made in equal numbers from the three heterospermically 'worst' bulls, the anticipated homospermic non-return rate would have been $63.44 \%$ and from the three 'best' bulls would have been $67.49 \%$. Small differences of this order are, nevertheless, economically important.

The reality of the statistically significant connection between heterospermic and homospermic index must be viewed after inspecting a certain skeleton in the cupboard. This is, that the homospermic differences between bulls were not quite formally significant $(0 \cdot 10>P>0.05)$, from which it might be argued that there are no real homospermic differences to predict (though this is not a necessary statistical conclusion). But it should be noted that the homospermic comparison of bulls at an A.I. Centre is necessarily biased, since less use must be made of a bull whose fertility appears to be declining, and the true differences between bulls tend, therefore, to be minimized. This may also be the reason why the indices of semen quality based on spermatozoan morphology and staining affinity predicted the homospermic index non-significantly, though in the right direction. Our conclusion is that the heterospermic method of assessing bull fertility can be taken seriously and is supported on comparative grounds by the work with mice and rabbits already mentioned.

The main result of the present work is that heterospermic insemination appears to be a good predictor of a piece of information vital to any A.I. Centre: the 'normal' homospermic fertility of bulls. The nature of the biological basis of the heterospermic test remains an open question. A simple hypothesis is that the proportion of live and dead spermatozoa varies between sires, and there is direct evidence for this in the rabbit (Beatty, 1960). Another hypothesis is 
that the test reveals sire differences in rate of capacitation, the more rapidly capacitated spermatozoa having a competitive advantage (Dziuk, 1965). The two hypotheses are not necessarily mutually exclusive; it is conceivable that the live spermatozoa of males with a high percentage of live spermatozoa are the more readily capacitated. We may, however, rule out two factors as major causes of the heterospermic differences between bulls. First, differential embryonic mortality up to 16 weeks can be excluded. The 16-week homospermic non-return rate for the ten bulls ranged from 60 to $69 \%$. Thus, prenatal mortality must lie somewhere between zero (at the least) and 31 to $40 \%$ (at the most) up to 16 weeks. There is no scope in these figures for an hypothesis based on prenatal mortality to 16 weeks and capable of giving a heterospermic difference between bulls as high as the observed maximum of 21-fold. Secondly, the existence of some bipaternal twin pairs rules out any 'all-or-none' effect in a given cow on the fertility of one of the constituents of the semen mixture.

What is the relative efficiency of heterospermic and homospermic evaluation of bull fertility? The homospermic method is expected to be relatively inefficient because over a wide range in semen quality there will be enough fertile spermatozoa to fertilize the majority of the eggs and, consequently, differences between bulls will be small. By contrast, the heterospermic method places spermatozoa in competition, only one spermatozoon, presumably from the most fertile ejaculate, fertilizing the egg. This will greatly exaggerate differences in fertility and the relative numbers of offspring should give an immediate reflection of relative semen differences. Further, the heterospermic comparison of bulls is made within dams, thus by-passing the numerous sources of error inherent in the between-dam comparisons of homospermic tests. An example based on representative conditions showed that the amount of labour, taken as the number of inseminations necessary, was estimated to be over 170 times less in the heterospermic test.

The initial spermatozoan concentration is correlated positively, highly and significantly with the log heterospermic index, but not with the homospermic nor any other index. It will be realized that the dilution of all semen collections to a standard concentration of $20 \mathrm{million} / \mathrm{ml}$ before making the mixed inseminates means that the dilution factor is an exact multiple of the initial concentration. The separate effects of initial concentration and degree of dilution cannot, therefore, be disentangled. Though a high initial concentration might well betoken some spermatozoan quality giving rise to a high heterospermic index, we can scarcely believe that the correspondingly high dilution factor could give such a rise, since increased dilution is generally taken to be harmful.

There are very high and significant correlations between the percentage capless (as defined earlier) on the one hand, and the three measures of staining affinity on the other hand. Presumably, all these variables are measures of the same thing, post-mortem change in the spermatozoa (Hancock, 1952; Buttle, Hancock \& Purser, 1965). The same explanation would apply to the high correlation between the percentage uniformly staining and the percentage part-stained, but a complication here is that these two variables were scored simultaneously on each slide and random technical and observational error from one slide to another could contribute artificially to the magnitude of the 
correlation. There is also an artificial element in the 'part-whole' correlations between total percentage stained and either percentage part-stained or percentage uniformly stained.

It is reasonable to conceive possible applications in order to guide future plans. The heterospermic test does seem to offer a promising and efficient method of predicting 'normal' sire fertility. But the heterospermic progeny cannot be scored until about 9 months after insemination, by which time the bulls may have been culled or their fertility may have changed. Heterospermic testing might be more useful in predicting the fertility of large uniform samples of bulked frozen semen whose fertility would not be expected to change materially with time. The time element being relatively unimportant, one could then visualize a routine heterospermic test of many frozen samples, carried out at times convenient to the A.I. Centre and involving quite small numbers of inseminations. Experiments on these lines are being initiated.

Finally, there is the well-known paradox that, although the obvious direct way of evaluating the homospermic fertility of a bull in terms of non-return rate or calving rate is to conduct homospermic test inseminations, the number of inseminations required to make a useful assessment of fertility is normally so large that the bull necessarily comes into large-scale use before his fertility is known. As an experiment, one might suggest selecting bulls for fertility primarily by their heterospermic performance. The indication from our work is that the actual heterospermic testing should not have a deleterious effect on the efficiency of an A.I. Centre, since the gross heterospermic non-return rate from the 508 heterospermic inseminations in the present work was at the satisfactory level of $68.1 \%$ (the homospermic non-return rate being $65.5 \%$ ) and the heterospermic calving rate was at the adequate level of $53.7 \%$. These figures are all the more satisfactory in that farmers are unlikely to have submitted their best cows to experimentation.

STATISTICAL APPENDIX

Semen attributes

The data for semen qualities in vitro constitute an incomplete 'randomized blocks' design within each series, the 'blocks' being the twenty-three occasions in Series 1 (or twenty-four in Series 2) when pairs of bulls were sampled, and the 'treatments' being the ten bulls. Because only two bulls were sampled per occasion, the interaction mean square has only 13 d.f. in Series 1 and 14 d.f. in Series 2. Exact least-squares analyses limited to Series 1 showed no real evidence that the 'occasions' represented any real source of variation. This justifies the simple process of successive averaging whereby the indices of semen attributes in Table 2 were obtained without reference to the 'occasions'. Because the full twenty-five combinations were not realized in either series, the indices are based on slightly different numbers of semen collections per bull, but this was ignored in calculating the unweighted regressions of Table 3.

\section{Heterospermic data}

Maximum likelihood estimates of bull constants were made by an iterative method (Rao, 1952) for each series separately, and also for the best fit to both 
series simultaneously. The members of twin pairs were treated as separate offspring. The constants were arranged arbitrarily to total 100 , and were then termed 'heterospermic indices'. The calculations were partially mechanized and most of the computation was contracted out to Independent Computer Services Ltd, Edinburgh. The results led to the analysis in Table 4, where expectations were frequently less than unity and it was necessary to carry out some pooling of the figures, thus reducing the d.f. for 'remainder' from 28 to 11 .

A null hypothesis is that the deviations of the forty-six pairs of figures in Table 1 from 1: 1 expectation represent merely sampling error. The high significance of the $\chi^{2}$ at the bottom of Table 4 makes the hypothesis untenable;

TABLE 4

ANALYSIS OF HETEROSPERMIC DATA OF TABLE 1

\begin{tabular}{|c|c|c|c|c|c|}
\hline Line & Item & d.f. & $\chi^{2}$ & \multicolumn{2}{|c|}{$\mathbf{P}$ and nature of significance test } \\
\hline$a$ & $\begin{array}{l}\text { Bull constants (hetero- } \\
\text { spermic indices) }\end{array}$ & 9 & $59 \cdot 6$ & 0.025 to 0.01 & $\begin{array}{l}\text { Variance ratio, } \\
\text { mean } \chi^{2}, \\
\text { lines } a, b\end{array}$ \\
\hline$b$ & Pooled error & 20\{ & 38.8\{ & $<0.001$ & Tabular $\chi^{2}$ \\
\hline$c$ & $\begin{array}{l}\text { Series/constants inter- } \\
\text { action }\end{array}$ & 9 & $21 \cdot 1$ & $>0 \cdot 25$ & $\begin{array}{l}\text { Variance ratio, } \\
\text { mean } \chi^{2}, \\
\text { lines } c, d\end{array}$ \\
\hline$d$ & Remainder & 11 & $17 \cdot 7$ & 0.1 to 0.05 & Tabular $\chi^{2}$ \\
\hline$e$ & $\begin{array}{l}\text { Total deviations from } \\
1: 1 \text { expectation }\end{array}$ & 29 & $98 \cdot 4$ & $<0.001$ & Tabular $\chi^{2}$ \\
\hline
\end{tabular}

Items to the right of a large bracket represent a partitioning of line $b$.

real deviations from $1: 1$ expectation must exist. These deviations are largely 'explained' by the variance associated with the joint maximum likelihood estimates in line $a$. There was assumed to be no real series/bull interaction $(P\rangle$ $0 \cdot 25$ ), and the $\chi^{2}$ for interaction and remainder were therefore pooled to give the pooled error term in line $b$. The significance of the differences between bull constants was tested against this pooled error. There was evidently some intangible error because line $b$ is itself significant, its $\chi^{2}$ being close to twice that expected from purely binomial variation. Therefore, by an ad hoc procedure, the standard errors of the bull constants resulting from the maximum likelihood computations were each multiplied by $\sqrt{ } 2$ before presentation in Table 2.

Because the heterospermic indices are nearly proportional to their standard errors, each index was transformed into $\log _{10}$ before calculating the correlations and regression mentioned in the text. The transformation tended to homogenize variance and also improved linearity of relationships with other variables. The heterospermic indices are not quite independent of one another, but this was ignored when calculating correlations and the regression.

\section{ACKNOWLEDGMENTS}

We are grateful to Dr B. Woolf for a computer program for $2 \times n$ heterogeneity $\chi^{2}$, to Professor Alan Robertson, F.R.s., for a correlation program, 
and to Dr J. Bouw (Wageningen, Netherlands) for blood-typing some of the parent animals.

\section{REFERENCES}

Beatty, R. A. (1957) A pilot experiment with heterospermic insemination in the rabbit. f. Genet. 55, 325.

Beatty, R. A. (1960) Fertility of mixed semen from different rabbits. F. Reprod. Fert. 1, 52.

Buttle, H. R. L., Hancock, J. L. \& Purser, A. F. (1965) Counting dead spermatozoa in frozen semen. Anim. Prod. 7, 59.

Cox, C. P. \& MELrose, D. R. (1953) The calibration of a photo-electric absorptionmeter for the rapid estimation of counts of spermatozoa in bull semen. F. agric. Sci., Camb. 43, 375.

Dzruk, P. J. (1965) Double mating of rabbits to determine capacitation time. F. Reprod. Fert. 10, 389.

EDWARDs, R. G. (1955) Selective fertilization following the use of sperm mixtures in the mouse. Nature, Lond. 175, 215.

HaNCOCK, J. L. (1952) The morphology of bull spermatozoa. F. exp. Biol. 29, 445.

Hancocx, J. L. (1957) The morphology of boar spermatozoa. Fl R. microsc. Soc. 76, 84.

Kushner, K. F. (1954) The effect of heterospermic insemination in animals and its biological nature (translated title). Bull. Acad. Sci. USSR, Ser. Biol., p. 32.

NAPIER, R. A. N. (1961) Fertility in the male rabbit. III. The estimation of spermatozoan quality by mixed insemination, and the inheritance of spermatozoan characters. $\mathcal{F}$. Reprod. Fert. 2, 273.

RAo, C. R. (1952) Advanced statistical methods in biological research. John Wiley, New York. 